\title{
KARAKTER NILAI INDEKS KOMPRESI SEKUNDER UNTUK TANAH DENGAN KANDUNGAN LANAU LEBIH DARI 50\%
}

\author{
Ricky Bunawan ${ }^{1}$, dan Gregorius Sandjaja Sentosa ${ }^{2}$ \\ ${ }^{1}$ Program Studi Sarjana Teknik Sipil, Universitas Tarumanagara, Jl. Letjen S. Parman No.1 Jakarta \\ Email: rickybunawan1998@gmail.com \\ ${ }^{2}$ Program Studi Sarjana Teknik Sipil, Universitas Tarumanagara, Jl. Letjen S. Parman No.1 Jakarta \\ Email: gregoriuss@ft.untar.ac.id
}

\begin{abstract}
ABSTRAK
Konsolidasi satu dimensi biasa terdiri dari 2 bagian utama yaitu, konsolidasi primer dan konsolidasi sekunder. Konsolidasi sekunder merupakan penurunan rata-rata yang terjadi setelah akhir dari penurunan primer. Konsolidasi sekunder biasanya terjadi dalam jangka waktu yang panjang, dan untuk pembangunan konstruksi dengan biaya yang mahal dan strategis seperti bandara, jalan tol, dan pelabuhan, perlu dilakukan prediksi kemungkinan terjadinya konsolidasi sekunder. Untuk menentukan kemungkinan terjadinya konsolidasi sekunder maka dibutuhkan Index Kompresi Konsolidasi Sekunder $\left(\mathrm{C}_{\alpha}\right)$. Penelitian ini menganalisis nilai $\mathrm{C} \alpha$ dari 4 daerah yang berbeda, dan membandingkan komposisi lanau dan lempung yang terkandung di dalam tanah dengan nilai hasil $\mathrm{C} \alpha$ yang didapat. Hasil analisis dari penelitian ini untuk mendapatkan angka $\mathrm{C} \alpha$ yang akan kelak dijadikan sebagai faktor keamanan untuk konsolidasi sekunder di daerah tersebut.
\end{abstract}

Kata kunci : Konsolidasi, Konsolidasi Sekunder, Lanau, Lempung, Indeks Kompresi Sekunder

\section{PENDAHULUAN}

\section{Latar Belakang}

Konsolidasi satu dimensi biasa terdiri dari 2 bagian utama yaitu, konsolidasi primer dan konsolidasi sekunder. Kurva hasil uji konsolidasi primer kurang lebih berbentuk huruf S yang digambar sebagai hubungan antara penurunan (settlement) vs. log waktu (log time) dan diasumsikan sebagai hasil dari disipasi bertahap tekanan air pori berlebih. Konsolidasi sekunder merupakan penurunan rata-rata yang terjadi setelah akhir dari penurunan primer.

Konsolidasi sekunder biasanya terjadi dalam jangka waktu yang panjang. Seperti salah satu contoh kasus yang terjadi adalah pembangunan bandara internasional Kansai (Mesri, 2015) yang dibangun di atas lahan reklamasi. Karena proyek ini merupakan proyek strategis yang perlu kestabilan dalam jangka panjang maka perlu dipastikan bahwa tidak akan terjadi penurunan dalam jangka panjang yang dapat merusak konstruksi bandara ini. Salah satu kerusakan yang potensial terjadi adalah penurunan dalam jangka panjang atau secondary settlement.

Dalam penelitian ini akan dilakukan perbandingan nilai $\mathrm{C}_{\alpha}$ beberapa tanah lunak yang diambil dari lokasi provinsi Banten, Jakarta Utara, dan Pontianak. Di lokasi Banten dan Jakarta Utara direncanakan akan dibangun jalur kereta api dan Runway pesawat yang diperkirakan akan mengalami penurunan jangka panjang atau secondary settlement.

Dikarenakan keterbatasan waktu maka uji konsolidasi menggunakan alat oedometer, maka dilakukan maksimum sampai 1 bulan dengan beban tertentu. Untuk pengujian ini sampel yang diambil adalah sampel terganggu (disturbed) dari 4 lokasi yang berbeda yaitu, Pandeglang, Pantai Indah Kapuk, Teluk Naga, dan Pontianak. Waktu pengujian di laboratorium UNTAR menggunakan alat oedometer.

Hasil penelitian diharapkan berupa Indeks Kompresi Sekunder, $\mathrm{C}_{\alpha}$, sebagai faktor keamanan konsolidasi sekunder yang akan dibandingkan dengan chart yang dihasilkan oleh Mesri (Mesri, 1973). 


\section{DASAR TEORI}

\section{Konsolidasi Tanah}

Menurut Braja M.Das (2001) bilamana suatu lapisan tanah jenuh air diberi penambahan beban, angka tekanan air pori akan naik secara mendadak. Pada tanah berpasir yang sangat tembus air (permeable). Air dapat mengalir dengan cepat sehingga pengaliran air - pori keluar sebagai akibat dari kenaikan tekanan pori dapat selesai dengan cepat. Keluarnya air dari dalam pori selalu disertai dengan berkurangnya volume tanah, berkurangnya volume tanah tersebut dapat menyebabkan penurunan lapisan tanah itu, Karena air pori didalam tanah berpasir dapat mengalir keluar dengan cepat, maka penurunan segera dan penurunan konsolidasi terjadi bersamaan.

Bilamana suatu lapisan tanah lempung jenuh air yang mampu mampat (compressible) diberi penambahan tegangan, maka penurunan (settlement) akan terjadi dengan segera.Koefisien rembesan lempung adalah sangat kecil dibandingkan dengan koefisien rembesan pasir sehingga penambahan tekanan air pori yang disebabkan oleh pembebanan akan berkurang secara lambat laun dalam waktu yang sangat lama. Jadi untuk tanah lempung-lembek perubahan volume yang disebabkan oleh keluarnya air dari dalam pori (konsolidasi) akan terjadi sesudah penurunan segera.

Pada umunya tanah, dalam bidang geoteknik, dibagi menjadi 2 jenis, yaitu tanah berbutir dan tanah kohesif. Pada tanah berbutir (Pasir/Sand), air pori dapat mengalir keluar struktur tanah dengan mudah, karena tanah berbutir memiliki permeabilitas yang tinggi. Sedangkan pada tanah kohesif (Clay), air pori memerlukan waktu yang lama untuk mengalir keluar seluruhnya. Hal ini disebabkan karena tanah kohesif memiliki permeabilitas yang rendah.

Secara umum, penurunan dapat diklasifikasikan menjadi 3 tahap, yaitu:

1. Penurunan Seketika (Immediate Settlement)

2. Penurunan Konsolidasi Primer (Primary Consolidation Settlement)

3. Penurunan Konsolidasi Sekunder (Secondary Consolidation Settlement)

\section{Konsolidasi Sekunder (Secondary Consolidation)}

Pada akhir konsolidasi primer (setelah tegangan air pori $\mathrm{U}=0$ ), penurunan pada tanah masih tetap terjadi sebagai akibat dari penyesuaian plastis butiran tanah. Tahapan konsolidasi ini dinamakan konsolidasi sekunder. Variasi angka pori dan waktu untuk penambahan beban akan sama seperti yang ditunjukkan pada gambar berikut.

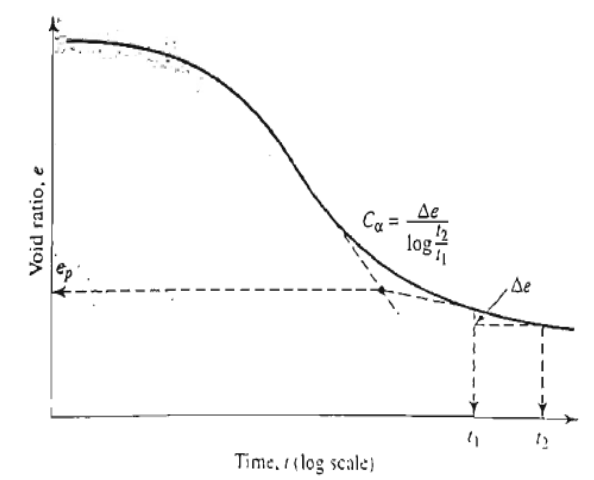

Gambar 1. Grafik Variasi angka pori dan waktu penambahan beban

Besarnya konsolidasi sekunder dapat dihitung dengan rumus :

$$
S s=C^{\prime} \alpha H \log \left(t_{2} / t_{1}\right)
$$

dengan,

$$
C \alpha=\frac{\Delta \mathrm{e}}{\log t_{2}-\log t_{1}}=\frac{\Delta \mathrm{e}}{\log \left(t_{2} / t_{1}\right)}
$$

dengan, $\mathrm{C}_{\alpha}=$ Indeks Pemapatan Sekunder, $\Delta \mathrm{e}=$ Perubahan angka pori, $\mathrm{t}=$ Waktu. 


$$
C^{\prime} \alpha=\frac{C \alpha}{1+e_{\mathrm{p}}}
$$

Dengan, $\mathrm{e}_{\mathrm{p}}=$ Angka pori pada akhir konsolidasi primer, $\mathrm{H}$ = tebal lapisan lempung, $\mathrm{m}$.

\section{METODOLOGI PENELITIAN}

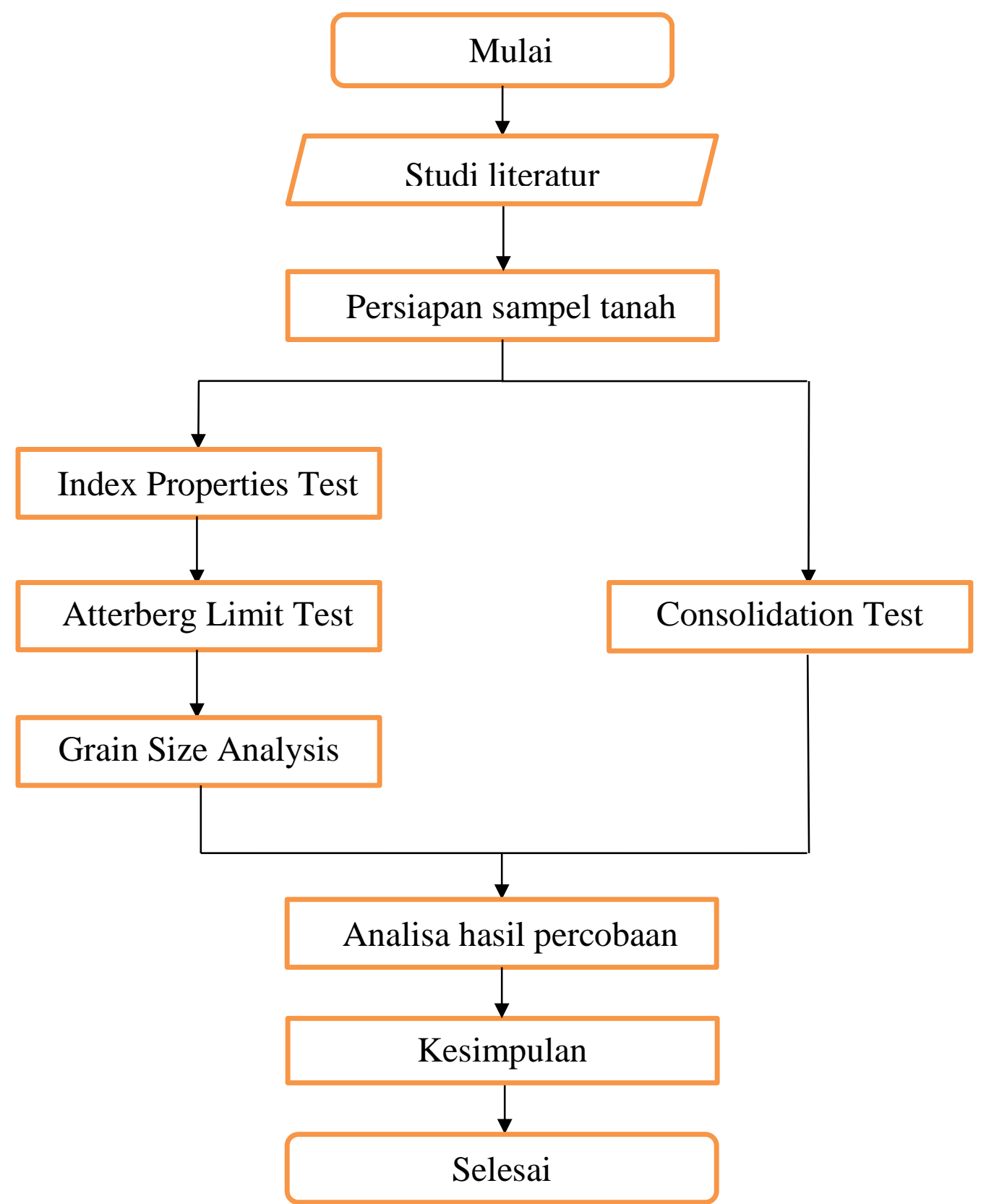

Gambar 2. Diagram Alir Penelitian 


\section{PENGUJIAN DAN ANALISIS HASIL}

\section{Pengujian Karakteristik}

Hasil dari pengujian karakteristik tanah untuk sampel dari beberapa lokasi di Indonesia, yaitu Pandeglang, Sawah Teluk Naga, Pantai Indah Kapuk, dan Pontianak. Terhadap sampel tanah tersebut dilakukan uji index properties meliputi specific gravity, atterberg limit, dan grain size dapat dilihat pada Tabel 1.

Tabel 1. Hasil Uji Karakteristik Tanah

\begin{tabular}{|c|c|c|c|c|}
\hline \multirow[b]{2}{*}{ Uji laboratorium } & \multicolumn{4}{|c|}{ BENDA UJI } \\
\hline & $\begin{array}{c}\text { Sawah } \\
\text { Pandeglang }\end{array}$ & $\begin{array}{c}\text { Sawah } \\
\text { Teluk } \\
\text { Naga }\end{array}$ & $\begin{array}{c}\text { Pantai Indah } \\
\text { Kapuk }\end{array}$ & Pontianak \\
\hline \multicolumn{5}{|l|}{ SPECIFIC GRAVITY } \\
\hline Gs & 2,64 & 2,6 & 2,54 & 2,52 \\
\hline \multicolumn{5}{|l|}{ ATTERBERG (batas plastis) } \\
\hline Batas Cair w $\mathrm{w}_{\mathrm{L}}(\%)$ & 80,02 & 61,81 & 59,74 & 68,25 \\
\hline Batas Plastis $\mathrm{w}_{\mathrm{P}}(\%)$ & 43,43 & 35,69 & 36,40 & 39,71 \\
\hline Indeks Plastisitas, $I_{p}(\%)$ & 36.59 & 26,12 & 23,44 & 28,54 \\
\hline \multicolumn{5}{|l|}{ GRAIN SIZE (ukuran butir) } \\
\hline Gravel (\%) & 1,2 & 3,62 & 1,36 & 0 \\
\hline Pasir (\%) & 18,48 & 32,73 & 30,69 & 2,53 \\
\hline Lanau (\%) & 66,05 & 56,53 & 59,38 & 61,79 \\
\hline Lempung (\%) & 15,48 & 10,74 & 9,94 & 35,69 \\
\hline Klasifikasi Tanah (AASHTO) & A-7 & A-7 & A-7 & A-7 \\
\hline Klasifikasi Tanah (USCS) & $\mathrm{OH}$ & $\mathrm{OH}$ & $\mathrm{OH}$ & $\mathrm{OH}$ \\
\hline
\end{tabular}

\section{Hasil Pengujian Konsolidasi Sekunder}

Hasil pengujian $\mathrm{C} \alpha$ di labotatorium dapat dilihat di Tabel 2 dan Gambar 3.

Tabel 2. Hasil Pengujian dengan Memperhatikan Komposisi Kandungan Lanau
Gradasi Butiran (\%)
$\mathrm{C} \alpha$

Lokasi

$\begin{array}{lllll}\text { Lanau } & \delta \mathrm{v}^{\prime}\left(\mathrm{kN} / \mathrm{m}^{2}\right) & \mathrm{C} \alpha_{1} & \mathrm{C} \alpha_{2} & \mathrm{C} \alpha_{3}\end{array}$

\begin{tabular}{|c|c|c|c|c|c|}
\hline \multirow{3}{*}{$\begin{array}{c}\text { Sawah Teluk } \\
\text { Naga }\end{array}$} & \multirow{3}{*}{56,53} & 41,38 & 0,0061 & 0,0309 & 0,0427 \\
\hline & & 151,72 & 0,0396 & 0,0447 & 0,0342 \\
\hline & & 594,51 & 0,0053 & 0,0070 & 0,0085 \\
\hline
\end{tabular}


Tabel 2. Hasil Pengujian dengan Memperhatikan Komposisi Kandungan Lanau (lanjutan)

\begin{tabular}{|c|c|c|c|c|c|}
\hline \multirow{2}{*}{ Lokasi } & \multicolumn{2}{|c|}{ Gradasi Butiran (\%) } & \multicolumn{2}{|c|}{$\mathrm{C} \alpha$} & \multirow[b]{2}{*}{$\mathrm{C} \alpha_{3}$} \\
\hline & Lanau & $\delta \mathrm{v}^{\prime}\left(\mathrm{kN} / \mathrm{m}^{2}\right)$ & $\mathrm{C} \alpha_{1}$ & $\mathrm{C} \alpha_{2}$ & \\
\hline \multirow{3}{*}{$\begin{array}{l}\text { Pantai Indah } \\
\text { Kapuk }\end{array}$} & \multirow{3}{*}{59,375} & 36,40 & 0,0315 & 0,0611 & - \\
\hline & & 139,16 & 0,0335 & 0,0341 & 0,0285 \\
\hline & & 580,66 & 0,0001 & 0,0011 & 0,0012 \\
\hline \multirow{3}{*}{ Pontianak } & \multirow{3}{*}{61,785} & 37,41 & - & - & - \\
\hline & & 154,19 & 0,0075 & 0,0105 & 0,0309 \\
\hline & & 621,85 & 0,0118 & 0,0068 & 0,0095 \\
\hline \multirow{3}{*}{$\begin{array}{c}\text { Sawah } \\
\text { Pandeglang }\end{array}$} & \multirow{3}{*}{66,045} & 38,53 & 0,0229 & 0,0631 & 0,0661 \\
\hline & & 142,93 & 0,0103 & 0,0102 & 0,0069 \\
\hline & & 585,53 & 0,0079 & 0,0060 & 0,0002 \\
\hline
\end{tabular}

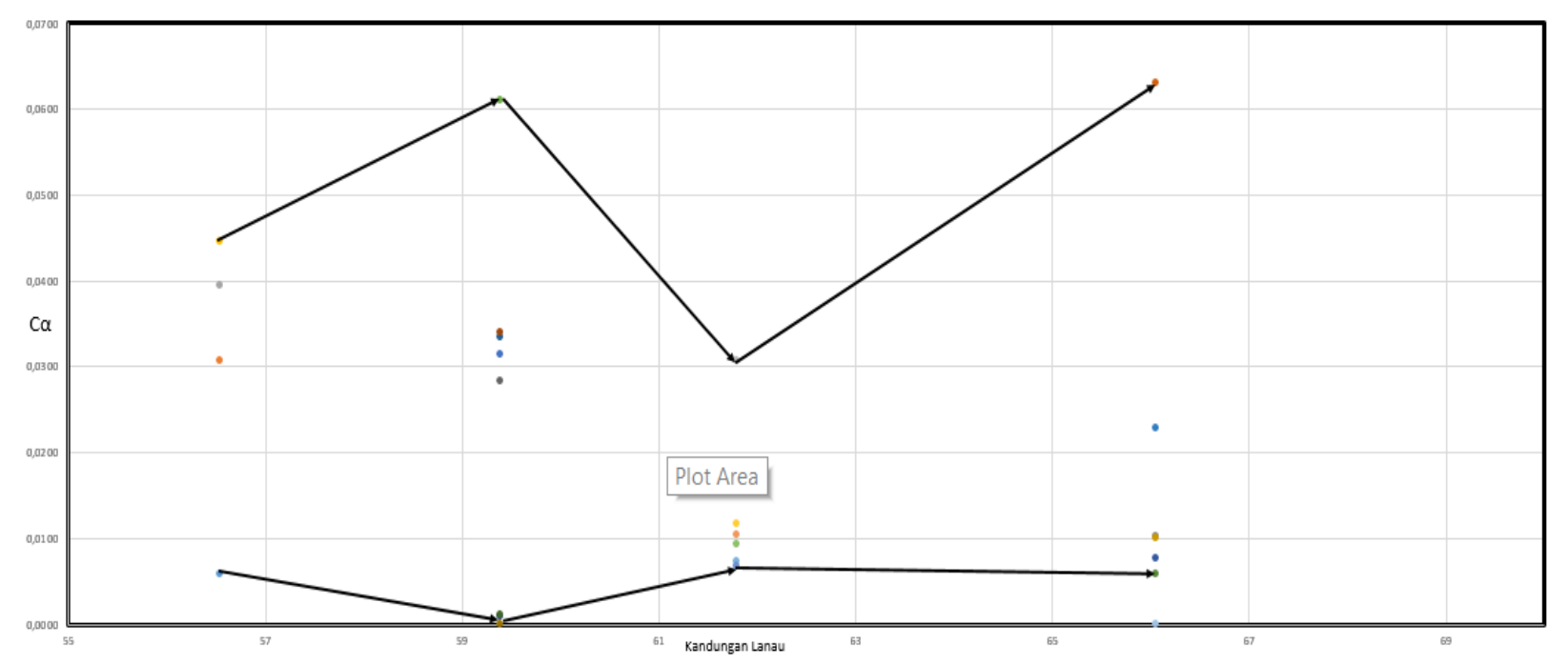

Gambar 3. Ca Tiap Daerah dengan Memperhatikan Komposisi Kandungan Lanau 


\section{Hasil Perbandingan dengan Chart Mesri 1973}

Hasil dari perbandingan nilai C $\alpha$ dengan Chart Mesri 1973 dapat dilihat di Gambar 4.

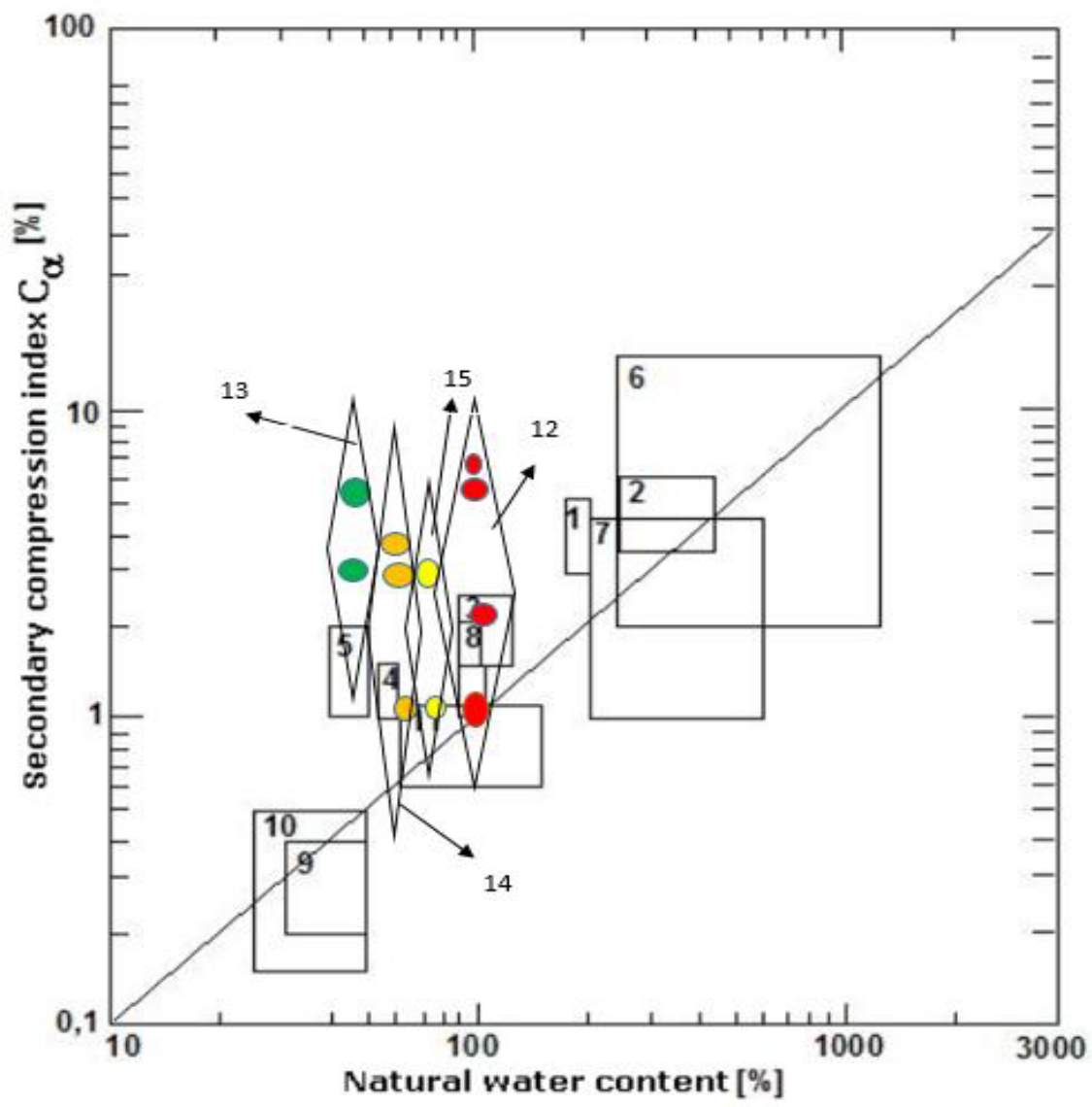

Gambar 4. Perbandingan Nilai C $\alpha$ dengan Chart Mesri 1973

Perbandingan indeks kompresi sekunder $(\mathrm{C} \alpha$ ) dari Pandeglang, Teluk Naga, Pantai Indah Kapuk, dan Pontianak kemudian dibandingkan dengan chart yang dihasilkan Mesri tahun 1973. Chart Mesri mencantumkan nilai C $\alpha$ yang diperoleh dari 11 lokasi dari berbagai negara, yaitu:

1.Whangamarino clay

2. Mexico City clay

3. Calcareous organic silt

4. Leda clay

5. Norwegian plastic clay

6. Amporphous and fibous peat

7. Canadian muskeg

8. Organic marine deposits

9. Boston blue clay

10. Chicago blue clay

11. Organic silt clay

Hasil nilai C $\alpha$ yang dihasilkan dari uji di laboratorium Mekanika Tanah UNTAR kemudian dicantumkan juga pada chart tersebut, tetapi dibedakan dengan diberi pembatas berupa kotak wajik, dan diberi nomor 12 sampai dengan 15 yang menginformasikan daerah tempat pengambilan sampel, yaitu:

12. Sawah Pandeglang silt

13. Pontianak silt

14. Sawah Teluk Naga silt

15. Pantai Indah Kapuk silt

Dari hasil perbandingan tersebut terlihat ada 4 titik nilai $\mathrm{C} \alpha$ yang berada dekat dengan garis usulan Mesri, sementara ada 7 nilai $\mathrm{C} \alpha$ agak jauh dari garis usulan Mesri. 


\section{KESIMPULAN}

Berdasarkan analisis yang dilakukan, dapat disimpulkan beberapa hal sebagai berikut:

1. Semakin besar kandungan lanau kecenderungan untuk rentang perbedaan $\mathrm{C} \alpha$ cenderung meningkat

2. Didapat nilai Indeks Kompresi Sekunder $(\mathrm{C} \alpha)$ terkecil adalah 0,000088 sedangkan nilai Indeks Kompresi Sekunder $(\mathrm{C} \alpha)$ yang terbesar adalah 0,0661

3. Dari 4 wilayah sampel yang memiliki kandungan komposisi lanau terbesar adalah wilayah Sawah Pandeglang

4. Semakin meningkat beban yang diberikan maka nilai $\mathrm{C} \alpha$ yang diperoleh semakin mengecil

5. Dari hasil perbandingan dengan chart Mesri, nilai $\mathrm{C} \alpha$ yang diperoleh ada yang mendekati dan ada yang berbeda jauh

\section{DAFTAR PUSTAKA}

Das, Braja M. (2001). Principles of Foundation Engineering $5^{\text {th }}$ Edition, PWS Publishing, Pasific Groove. Mesri, G. (1973). Coefficient of Secondary Compression, Journal of the Soil Mechanics and Foundation Division, ASCE, Vol. 99, No. SMI, 123- 137.

Mesri, G., J.R.Funk. (2015).Settlement of the Kansai International Airport Islands, J.Geotech. Geoenviron. Eng, 141(2): 04014102(ASCE), 1-16, Reston ,Virginia, USA. 
Karakter Nilai Indeks Kompresi Sekunder Untuk Tanah

Ricky Bunawan, et al. dengan Kandungan Lanau Lebih dari 50\% 